\title{
Internet como ferramenta de apoio no ensino odontológico: avaliação da aptidão técnica dos estudantes de graduação da Faculdade de Odontologia da Universidade de São Paulo
}

\author{
Internet as a support tool in the dentistry education: \\ evaluation of technical skills from the graduation students of \\ the School of Dentistry at University of São Paulo
}

\author{
Fábio Massaharu Nogi ${ }^{1}$, Rodolfo Francisco Haltenhoff Melani ${ }^{2}$
}

\begin{abstract}
Nogi, FM e Melani RFH. Internet como ferramenta de apoio no ensino odontológico: avaliação da aptidão técnica dos estudantes de graduação da Faculdade de Odontologia da Universidade de São Paulo. Saúde, Ética \& Justiça. 2009; 14(2):84-91.

Resumo: A disseminação da Internet a partir dos anos 90 tem determinado alterações substanciais na dinâmica das interações sociais, contribuindo para a formação de uma cultura globalizada, na qual o trânsito de informações e conhecimentos se processa através de novos paradigmas de comunicação. Diante desse quadro, o impacto da Internet na formação profissional tem sido amplamente discutido em diversas áreas do conhecimento, com o intuito de se instituir diretrizes e protocolos que possam fornecer o arcabouço necessário para a elaboração de projetos de Educação On-Line eficientes. O escopo deste estudo foi analisar a viabilidade de utilização da Internet como instrumento de apoio a aulas presenciais no processo de ensino-aprendizagem em Odontologia. Com essa finalidade, procedeu-se à aplicação de um questionário versando sobre o manejo do computador e da Internet em 143 alunos da Faculdade de Odontologia da Universidade de São Paulo (FOUSP), que cursavam o $2^{\circ}$ e o $8^{\circ}$ semestres da graduação no período diurno. Após a análise das respostas, os autores concluíram que os estudantes avaliados demonstraram boa aptidão técnica no manejo de computadores e da Internet, estando aptos para utilizar a Internet como ferramenta de auxílio pedagógico em sua formação profissional.
\end{abstract}

DESCRITORES: Educação; Educação continuada em odontologia; Informática odontológica/educação; Internet/ utilização.

\footnotetext{
1 Mestre em Odontologia Social pela Faculdade de Odontologia da Universidade de São Paulo.

2 Professor Doutor do Departamento de Odontologia Social da Universidade de São Paulo.

Endereço para correspondênCiA: Fábio Massaharu Nogi. Rua Artur Dias, 284. CEP 04150-070. Jardim da Saúde, São Paulo, SP. E-mail: fabiomnogi@yahoo.com.br
} 
Nogi FM, Melani RFH. Internet como ferramenta de apoio no ensino odontológico

INTRODUÇÃO

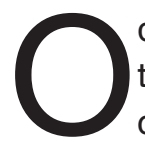
desenvolvimento acelerado das tecnologias de informação e comunicação, aliado ao menor custo dos computadores e de seus acessórios, tem proporcionado uma ampla disseminação da informática, alterando a dinâmica dos processos, serviços e interações sociais que compreendem o cotidiano das pessoas. Vivemos na Era da Informação, na qual o conhecimento se multiplica instantaneamente, adquirindo valor de mercadoria altamente requisitada em qualquer área profissional. De acordo com Shapiro e Hugues, ${ }^{7} 50 \%$ do conhecimento técnico, em qualquer campo da ciência, torna-se obsoleto em um prazo médio de 5 anos.

Nesse contexto, os cirurgiões-dentistas necessitam de acesso rápido a bases confiáveis de conhecimento técnico e científico, sendo imprescindível o uso da informática em sua rotina clínica.

O emprego das Novas Tecnologias de Informação e Comunicação (NTIC) e a instituição de projetos de Educação a Distância (EAD) têm sido preconizados por autores de diversas áreas como uma alternativa capaz de suprir, ao menos parcialmente, as deficiências no processo de ensino-aprendizagem, através do estímulo à auto-aprendizagem.

Mattheos et al. ${ }^{5}$ defendem que os benefícios obtidos com a aplicação das NTIC no ensino odontológico são evidentes. Internet, banco de dados on-line, e-mail, vídeo digital, aprendizagem assistida por computador (AAC) e classes virtuais são alguns dos recursos elencados por estes autores, que sugerem o elevado potencial dessas tecnologias quando aplicadas na graduação. Essa riqueza na oferta de recursos e a superação das barreiras espaços-temporais favorecem o estudo autodirigido, conferindo maior autonomia para o estudante.

A utilização de computadores e dos recursos multimídia, segundo Lowe et al. ${ }^{4}$, pode auxiliar o estudo autodirigido permitindo aos estudantes um pleno controle sobre o conteúdo, tempo, local, e ritmo de aprendizagem.

A Internet, segundo Almeida ${ }^{1}$, pode atuar como instrumento para a rápida distribuição de informações, ou como ferramenta para concretizar o intercâmbio de informações entre as pessoas por meio de sua interatividade. A estrutura hipertextual da rede disponibiliza um leque de possibilidade no processo de obtenção da informação, permitindo ao usuário interligar as informações conforme os seus próprios interesses e necessidades, navegando e construindo seqüências personalizadas em suas pesquisas.

No entanto, a despeito do desenvolvimento e das potencialidades das novas tecnologias, o uso efetivo dessas ferramentas requer conhecimentos básicos e a aquisição mínima de habilidades pelos seus usuários ${ }^{6}$.

A avaliação dos conhecimentos e habilidades dos estudantes no manejo de computadores e da Internet é uma medida que deve anteceder a elaboração de qualquer projeto de EAD, mediado pela rede. Com esse intuito, Corrêa ${ }^{2}$ procedeu à aplicação de um questionário, entre os alunos de graduação da Faculdade de Odontologia da Universidade de São Paulo, cursantes das disciplinas de Patologia. A partir dos resultados obtidos, a autora concluiu que os estudantes avaliados estavam aptos tecnicamente e desejavam submeter-se a uma sistemática de ensino a distância, utilizando a Internet como veículo de transmissão de informações.

O diagnóstico das aptidões dos alunos em relação à Internet forneceu subsídios para que Corrêa et al. ${ }^{3}$ elaborassem um curso de cirurgia oral baseado na Internet, no qual as atividades cirúrgicas foram desenvolvidas em casa, longe do ambiente escolar e sem a interferência do professor. Após a conclusão do curso, observouse que todos os estudantes terminaram os passos propostos dentro do tempo esperado. Esse resultado foi creditado pelos autores ao elevado potencial de auto-aprendizagem intrínseco aos recursos de hipertexto e ao uso de computadores pessoais. Porém, a realização de incisões e suturas tecnicamente inadequadas levou os pesquisadores a preconizarem esta modalidade de ensino somente para os estudantes que já tivessem participado de cursos convencionais de cirurgia, nos quais estes conteúdos tenham sido transmitidos diretamente pelo professor. 
Nogi FM, Melani RFH. Internet como ferramenta de apoio no ensino odontológico

O escopo deste estudo é avaliar os conhecimentos e habilidades, em relação ao manejo de computadores e da Internet, dos estudantes dos $2^{\circ}$ e $8^{\circ}$ semestres da Faculdade de Odontologia da Universidade de São Paulo, analisando as particularidades e diferenças nos perfis dos usuários destes grupos.

Procedemos, também, a uma análise comparativa dos resultados obtidos neste estudo com os dados levantados pelo trabalho de Corrêa ${ }^{2}$, no intuito de comprovar a aquisição de maior capacitação técnica por parte dos estudantes, demonstrando que estes se apresentam mais familiarizados às estruturas hipertextuais e aptos a participar de projetos de ensino a distância, via Internet.

\section{MATERIAL E MÉTODOS}

Um questionário foi entregue aos alunos de graduação dos $2^{\circ}$ e $8^{\circ}$ semestres, período diurno, da Faculdade de Odontologia da Universidade de São Paulo (FOUSP). Este procedimento foi realizado com o propósito de avaliar o grau de fluência digital e de familiaridade com a Internet dos graduandos de odontologia.

O questionário foi elaborado tendo como modelo o levantamento realizado por Corrêa ${ }^{2}$. Os dados obtidos foram comparados com os resultados registrados pela autora, para estimar mudanças nos perfis de uso de computadores e da rede pelos graduandos da FOUSP.

\section{Resultados}

O questionário foi aplicado aos alunos dos $2^{\circ}$ e $8^{\circ}$ semestres, período diurno, do curso de Odontologia da Universidade de São Paulo. A pesquisa foi respondida por 70 alunos do $2^{\circ}$ semestre e por 43 alunos do $8^{\circ}$ semestre.

Os aplicativos mais utilizados pelos graduandos estão representados no Gráfico 1 . Observa-se que a quase totalidade dos alunos relatou fazer uso rotineiro de processadores de texto. Porcentagens significativas de estudantes assinalaram que utilizam, freqüentemente, softwares que proporcionam entretenimento, jogos, multimídia em geral e programas para apresentação, como o Microsoft PowerPoint $®$.
A freqüência de acessos à Internet por semana está ilustrada no Gráfico 2. Notase, em ambos os semestres, a ausência de estudantes que nunca utilizaram a Internet, e uma pequena parcela de graduandos que acessam a Internet de forma esporádica (4\% para os que estavam cursando o $2^{\circ}$ semestre e $2 \%$ para os do $8^{\circ}$ semestre).

Em relação à quantidade de horas que o aluno permanece conectado à Internet (Gráfico 3), verifica-se que, de modo geral, os estudantes do $2^{\circ}$ semestre despendem mais tempo em seus acessos. Cerca de $17 \%$ dos estudantes do $2^{\circ}$ semestre, contra $7 \%$ do $8^{\circ}$ semestre, relataram que utilizam a Internet durante mais de 10 horas semanais.

O Gráfico 4 representa as principais finalidades de utilização da Internet, segundo os participantes da pesquisa. Verifica-se que, para ambos os grupos, a utilização do correio eletrônico (e-mail) prevalece como a finalidade principal no acesso a Internet, seguido da navegação pelos sites. O emprego da Internet como instrumento de comunicação em tempo real é significativamente mais expressiva entre os estudantes do 2 응 semestre (49\%, em comparação a $23 \%$ do 8 은 semestre). Os estudantes do $8^{\circ}$ semestre, por sua vez, demonstraram um maior interesse na utilização do Orkut $囚(40 \%)$ em relação aos participantes do $2^{\circ}$ semestre (16\%). O Orkut $\circledast$ é um programa que permite o estabelecimento de uma rede de relacionamentos, possibilitando a formação de comunidades virtuais e de fóruns conforme as áreas e temas de interesse de cada usuário.

O Gráfico 5 indica que $70 \%$ dos estudantes do $8^{\circ}$ semestre informaram que utilizam a Internet com o propósito de aprimorar os seus conhecimentos em odontologia. Essa porcentagem cai para $43 \%$ entre os estudantes do $2^{\circ}$ semestre.

Ao avaliarmos quais características de um site os alunos consideram mais relevantes, observouse uma certa similaridade na ordenação das respostas, sendo notória, entretanto, a maior importância atribuída à fidedignidade das fontes bibliográficas entre os graduandos do $8^{\circ}$ semestre. Essa mesma característica é listada na quarta posição, entre os estudantes do $2^{\circ}$ semestre, após 
Nogi FM, Melani RFH. Internet como ferramenta de apoio no ensino odontológico

Gráfico 1 - Aplicativos mais utilizados pelos alunos dos $2^{\circ}$ e $8^{\circ}$ semestres, período diurno, da FOUSP

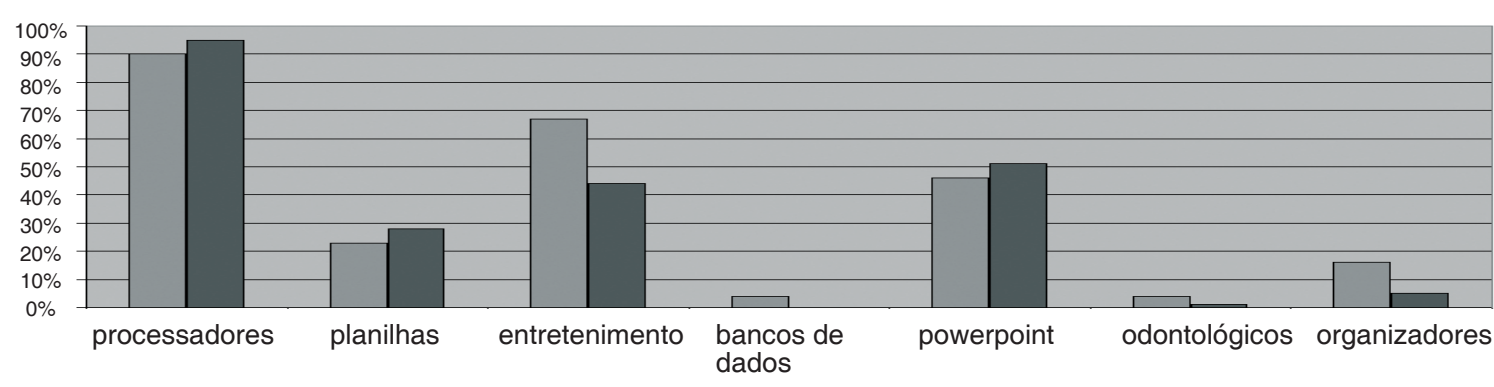

Gráfico 2 - Freqüência semanal de acesso à Internet dos alunos (número, em média, de acessos por semana)

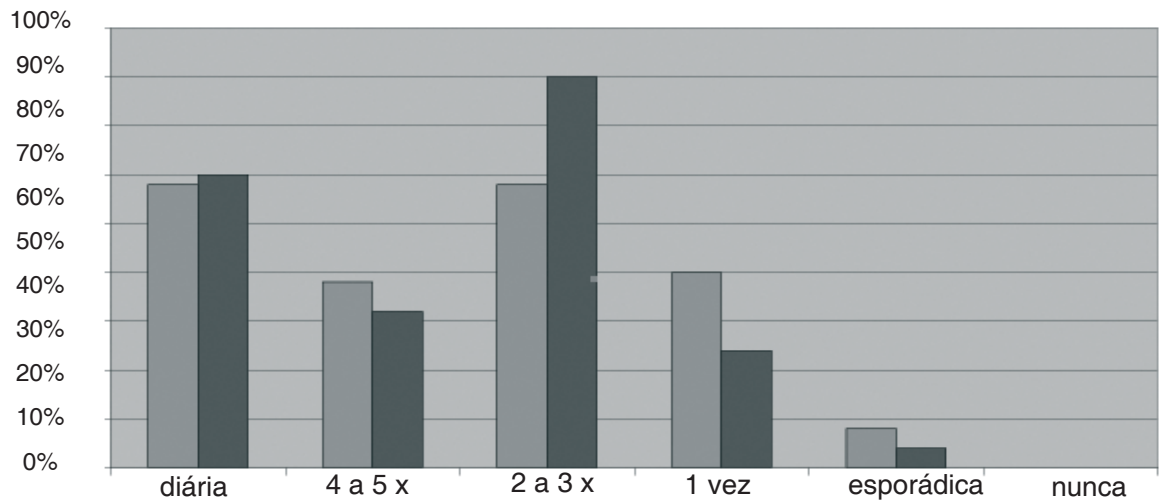

Gráfico 3 - Quantidade de horas que os alunos permanecem conectados a Internet por semana, em média

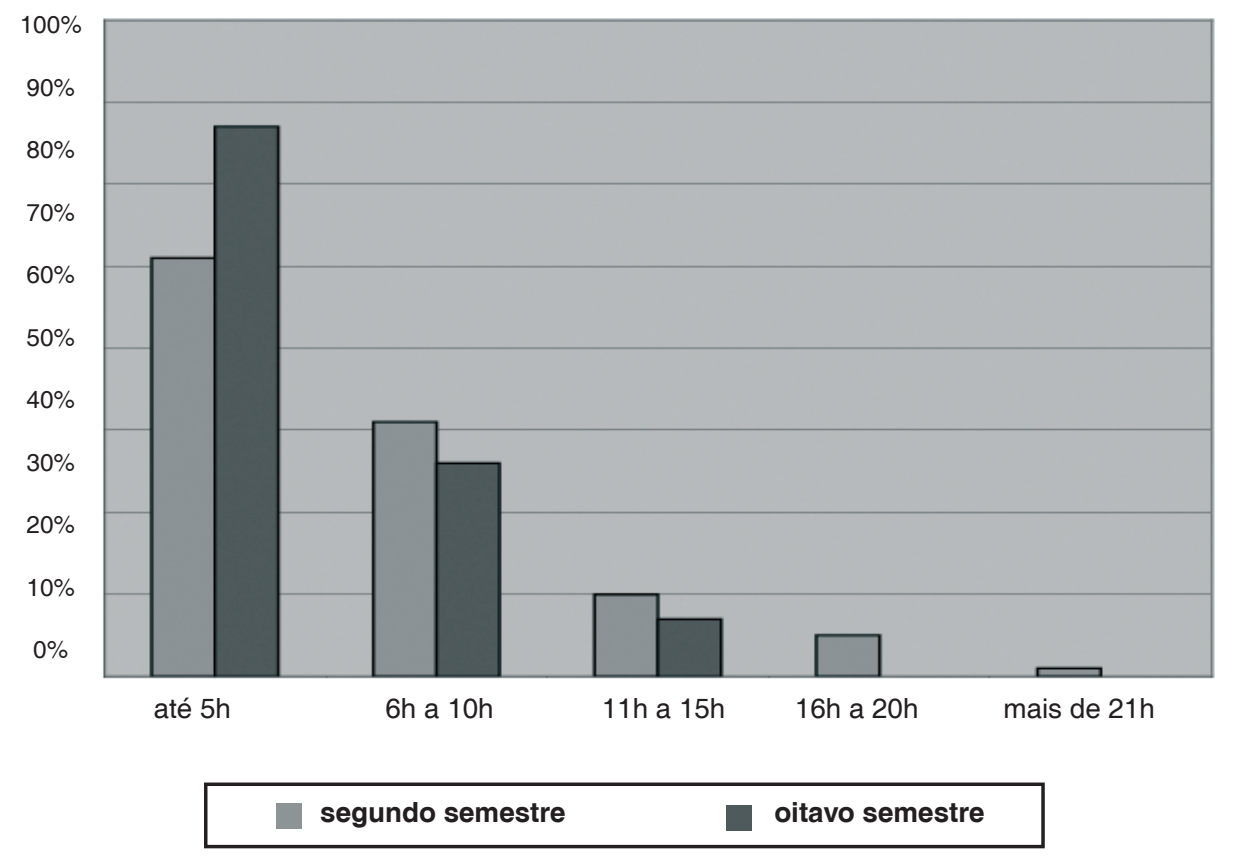


Nogi FM, Melani RFH. Internet como ferramenta de apoio no ensino odontológico

propriedades relacionadas à funcionalidade do site. As demais características não apresentaram diferenças significativas quanto à sua ordenação, destacando-se que, para ambos os grupos, a disposição de tecnologias sofisticadas pelo site não parece ser um fator relevante ou decisivo em sua escolha. $\mathrm{O}$ Gráfico 6 registra essas respostas dos estudantes do $2^{\circ}$ e $8^{\circ}$ semestres de forma comparativa.

\section{DISCUSSÃO}

A avaliação das habilidades e conhecimentos dos alunos, em relação ao manejo do computador e da Internet, é de extrema importância para que se possa averiguar a viabilidade em se instituir projetos de EAD que sejam pertinentes para os estudantes de uma determinada instituição de ensino. O questionário elaborado com essa finalidade teve como base o trabalho desenvolvido por Corrêa ${ }^{2}$.

O Gráfico 2 registra um avanço surpreendente em relação aos dados obtidos no estudo de 2001: todos os estudantes que participaram da pesquisa acessam a Internet, sendo que mais de $95 \%$ dos graduandos do 2 o semestre e $97 \%$ do $8^{\circ}$ semestre acessam a Internet ao menos uma vez por semana. Destaca-se, também, que cerca de $30 \%$ dos estudantes afirmam utilizar a Internet diariamente. No estudo de Corrêa (2001), a porcentagem de alunos que indicaram ter uma freqüência diária de acesso era em torno de $18 \%$ dos pesquisados. Cremos que esse avanço pode ser creditado aos menores custos para aquisição de computadores e manutenção do acesso à Internet, além do maior conhecimento de informática por parte dos estudantes.

Outro dado relevante é que, embora a freqüência de acesso seja semelhante para ambos os grupos, os estudantes do $8^{\circ}$ semestre despendem menos tempo em suas conexões à Internet. $49 \%$ dos estudantes do $2^{\circ}$ semestre, em comparação a $33 \%$ dos alunos do $8^{\circ}$ semestre, permanecem conectados à rede por mais de 5 horas semanais (Gráfico 3). Essa diferença pode ser atribuída a uma utilização mais racional da rede pelos estudantes em final de curso, indicando um maior direcionamento na busca de informações e na utilização da Internet.
O maior domínio em informática, relatado anteriormente, pode ser atestado pelos resultados expressos no Gráfico 5.1. 95\% dos estudantes do $8^{\circ}$ semestre, assim como $90 \%$ dos estudantes do $2^{\circ}$ semestre, assinalaram que fazem uso rotineiro de softwares de processamento de texto. Corrêa, em 2001, verificou que pouco mais de $30 \%$ dos graduandos da FOUSP demonstraram ter conhecimento do Microsoft Word®. De modo geral, constatamos um aumento surpreendente no percentual de estudantes que fazem uso de softwares variados em relação à pesquisa de 2001.

Ao averiguar quais as principais formas de utilização da Internet realizadas pelos alunos, Corrêa $^{2}$ constatou que a maioria dos estudantes indicou a consulta de sites e o e-mail, com $28 \%$ e $33 \%$ das respostas. Verificamos que estas continuam sendo as principais formas de utilização da Internet e observamos um aumento significativo nessas porcentagens. $87 \%$ e $68 \%$ dos estudantes assinalaram, respectivamente, a utilização dos serviços de e-mail e a navegação por sites como as principais finalidades no acesso à Internet.

O Gráfico 4 confirma a maior adesão dos alunos do $2^{\circ}$ semestre aos softwares de comunicação em tempo real. Podemos aventar que este fato pode ser indicativo da exploração do novo contexto social por parte dos estudantes do $2^{\circ}$ semestre, que iniciaram a sua vida universitária e, portanto, enfrentam novos desafios relacionais.

Outro dado de extrema relevância é o fato de $100 \%$ dos entrevistados afirmarem que fazem uso do e-mail como instrumento de comunicação. No questionário de 2001, somente cerca de $35 \%$ dos pesquisados selecionaram o e-mail como uma das principais formas de utilização da Internet. Esse dado corrobora com a idéia de que a Internet popularizou-se como ferramenta de comunicação interpessoal.

Ao questionarmos os alunos em relação ao uso da Internet para a reciclagem e aprofundamento de conhecimentos em Odontologia (Gráfico 5), cerca de $70 \%$ dos estudantes do $8^{\circ}$ semestre informaram que utilizam a Internet com esse propósito, indicando uma maior maturidade na utilização da rede por parte destes. Entre os 
Nogi FM, Melani RFH. Internet como ferramenta de apoio no ensino odontológico

Gráfico 4 - Principais finalidades da utilização da Internet segundo os alunos

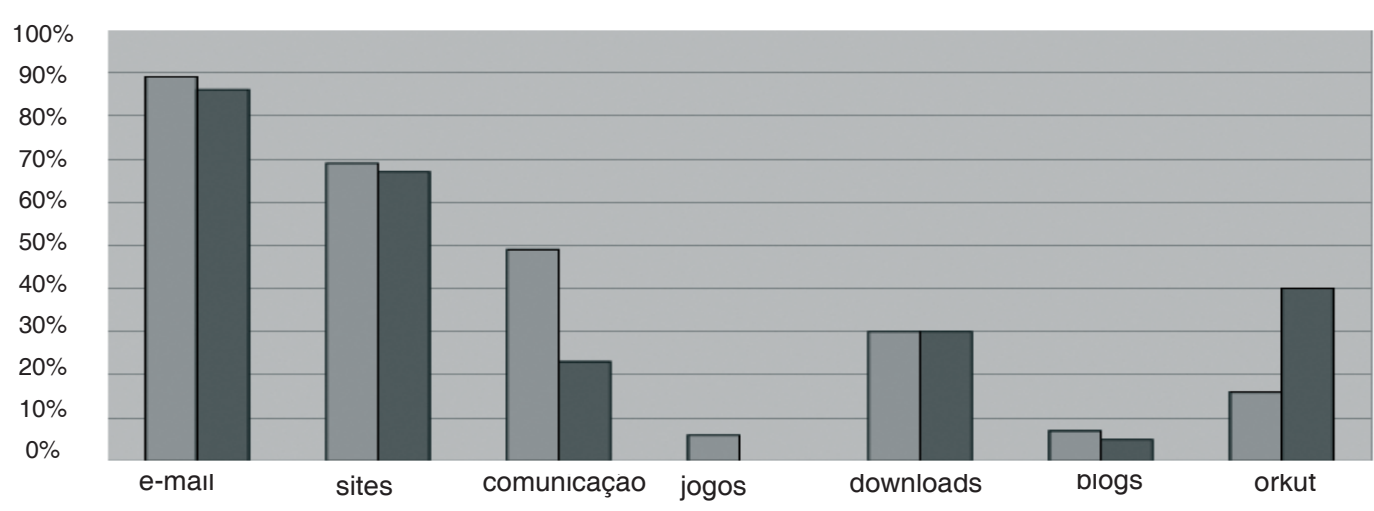

Gráfico 5 - Porcentagem de alunos, que utilizam (sim) ou não utilizam (não) a Internet como instrumento de atualização de seus conhecimentos

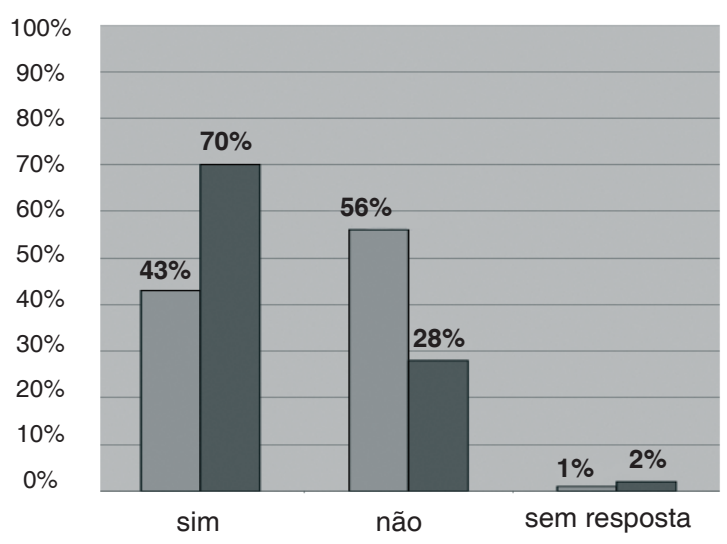

Gráfico 6 - Principais características que um site deve apresentar segundo respostas dos estudantes (gráfico comparativo)

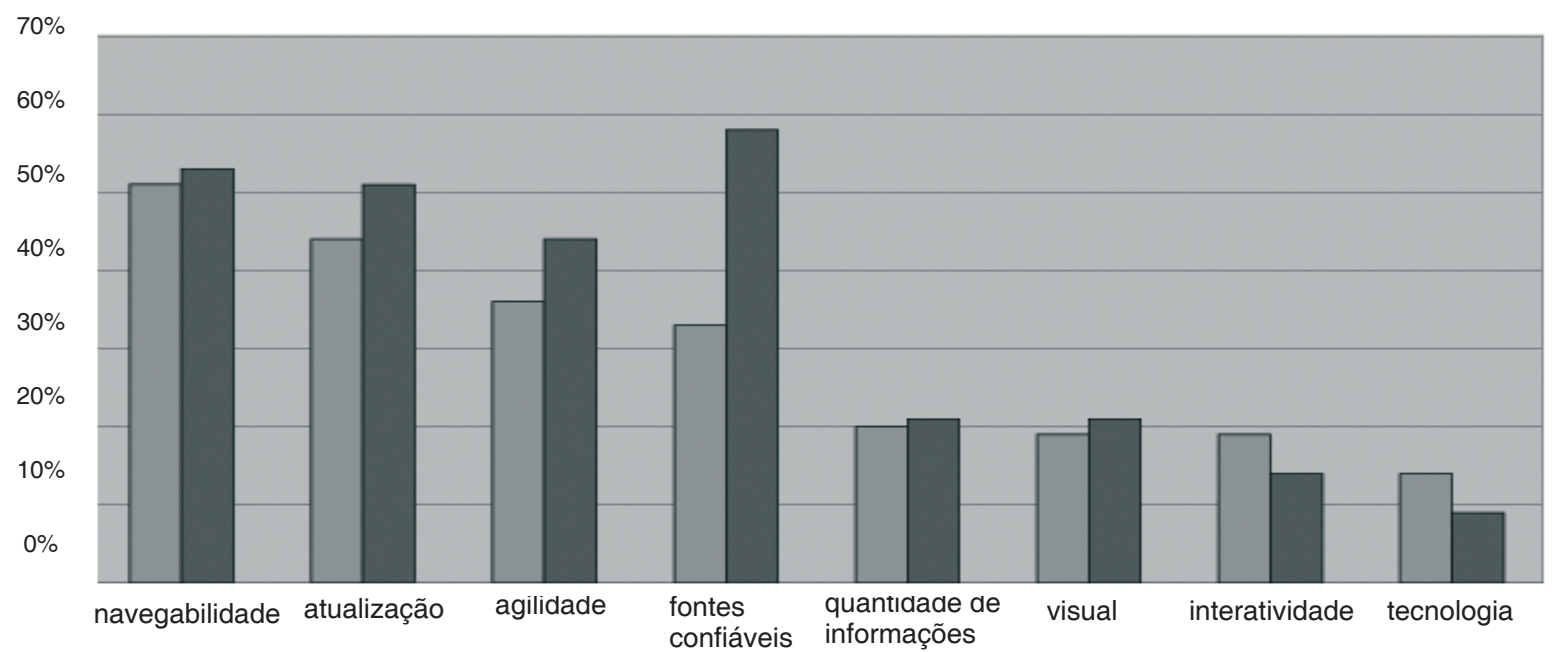


Nogi FM, Melani RFH. Internet como ferramenta de apoio no ensino odontológico

estudantes do $2^{\circ}$ semestre, essa porcentagem cai para $43 \%$.

A utilização mais racional da Internet pelos estudantes do $8^{\circ}$ semestre também pode ser presumida pelas características mais importantes de um site, segundo as opiniões dos participantes do presente estudo (Gráfico 6). Verifica-se que a diferença mais contrastante, em relação às preferências de ambos os grupos, recai sobre a importância atribuída à confiabilidade das fontes utilizadas na composição do conteúdo do site. Enquanto para os graduandos do $2^{\circ}$ semestre este item está posicionado em quarto lugar, para os alunos do $8^{\circ}$ semestre esta característica é apontada como a mais relevante na constituição de um site.

A importância atribuída à consistência bibliográfica de um site evidencia um maior juízo crítico e uma maior consciência científica em relação às informações disseminadas na rede. Esta postura crítica é extremamente desejável, considerando que uma das mais freqüentes advertências relativas ao uso da Internet, como instrumento de ensino, diz respeito à não-confiabilidade das fontes consultadas. Observa-se que, à exceção do posicionamento deste item, a ordem de preferência das demais características não se alterou ao se comparar um grupo com o outro. Outro dado digno de nota é o pequeno valor atribuído ao emprego de tecnologias sofisticadas na construção do site para ambos os grupos.

\section{CONCLUSÃO}

Os estudantes de graduação em Odontologia da FOUSP estão habituados ao manejo de computadores e da Internet, demonstrando capacitação técnica e cognitiva para a utilizarem como veículo de transmissão de informações e como ferramenta de auxílio pedagógico na aprendizagem e aprofundamento de conteúdos.

A análise comparativa dos resultados obtidos neste estudo com os dados fornecidos pelo trabalho de Corrêa evidencia a aquisição de maior consciência e capacitação técnica por parte dos alunos de graduação da FOUSP, comprovando a familiaridade dos estudantes com as estruturas hipertextuais. Observa-se, também, uma maior maturidade no uso da rede à medida que o estudante avança em seu curso de graduação.

Nogi, FM e Melani RFH. Internet as a support tool in the dentistry education: evaluation of technical skills from the graduation students of the School of Dentistry at University of São Paulo. Saúde, Ética \& Justiça. 2009;14(2):84-91.

AвStRACT: The Internet spread since the 1990s has given substantial changes in the dynamics of social interactions, being responsible for the development of a globalized culture in which traffic of information is processed by new communication paradigms. Therefore the impact of the Internet regarding professional formation has been discussed by several outlines of knowledge - in order to establish guidelines and protocols that can provide the basic frameworks for efficient Online Education projects. This study aimed at providing a feasibility analysis of resorting the Internet as a support tool for presencial courses in the teaching-learning process in Dentistry. 143 morning classes students from the School of Dentistry at University of São Paulo(FOUSP) - 70 of them attending their second semester and 43 attending their eighth semester - took the survey about Internet and Computer knowledge. Results show that the evaluated public got good skills to use the Internet as a pedagogical tool in their professional formation.

KEY wORDS: Education, dental, continuing; Education; Internet/utilization; Dental informatics/education.

REFERÊNCIAS

1. Almeida MEB. Educação a distância na Internet: abordagens e contribuições dos ambientes digitais de aprendizagem. Educ
Pesq. 2003;29(2):327-40.

2. Corrêa L. Análise da mudança de paradigma do ensino de graduação em patologia na 
Nogi FM, Melani RFH. Internet como ferramenta de apoio no ensino odontológico

odontologia: proposta de ensino-aprendizado a distância via Internet [Tese]. São Paulo: Faculdade de Odontologia da USP; 2001.

3. Corrêa L, Campos AC, Souza SCOM, Novelli MD. Teaching oral surgery to undergraduate students: a pilot study using a Webbased practical course. Eur J Dent Educ. 2003;7:111-5.

4. Lowe Cl, Wright JL, Bearn DR. Computer-aided learning (CAL): an effective way to teach the index of orthodontic treatment need (IONT)? J Orthod. 2001;28:307-11.
5. Mattheos N, Nattestad A, Schittek M, Attström R. Computer literacy and attitudes among students in 16 European dental schools: current aspects, regional differences and future trends. Eur J Dent Educ. 2002;6:30-5.

6. Plasschaert AJ, Wilson NH, Cailletau JG, Verdonschot EH. Opinions and experiences of dental students and faculty concerning computer assisted learning. J Dent Educ. 1995;59:1034-40.

7. Shapiro J, Hugues S. Information technology as a liberal art. Educom Rev. 1996;31:31-5. 